\title{
Translation of Address Terms in Hongloumeng Through Relevance Theory*
}

\author{
YAN Xue-qin \\ Beijing University of Posts and Telecommunications, Beijing, China; \\ Beijing Foreign Studies University, Beijing, China
}

\begin{abstract}
Translation of address terms is a very significant part in the translation of literary works. Yet the agreement on how to do their translation has not been settled. This thesis will make a detailed comparison of the translation of address terms in the extracted examples from Hongloumeng from the perspective of relevance theory (RT). It is believed that address terms are closely context- and culture-bounded, so there is no settled results for the translation of a particular address term. But the there are general rules to direct their translation from the perspective of RT by focusing on the context and the writer's intention.
\end{abstract}

Keywords: address terms, relevance theory, writer’s intention

\section{Introduction}

Address terms carry rich and abundant implications and are very culture-specific, so it is very hard to keep their cultural features while reserving their implications in their translation. How to balance the two during their translation is of the top concern of the translators. Hongloumeng is the peak of Chinese classical novel in which Cao Xueqin, author of this novel, portrayed about 1,000 characters through dialogues. Address terms, as an indispensable part of human communication, appeared frequently in the dialogues of this book, which is of great importance for the depiction of the characters. So Hongloumeng is an ideal material to study the translation of address terms. This thesis intends to make proposals on how to deal with address terms' translation from the perspective of relevance theory (RT).

\section{Literature Review}

\section{Previous Accounts of Address Term and Its Translation}

Address term is an extinguished social and language phenomenon which emerged at the request of human communication. This thesis studies address terms in people's communication activities. With its communication end, address term is born with two roles: (1) referential use; and (2) addressing use, the former referring to others beyond the communication activity and the latter addressing the participants of the communication activity (Hu,

\footnotetext{
* Acknowledgements: I’d like to acknowledge support from ZHENG Chun-ping, Assistant Professor, School of Humanities, Beijing University of Posts and Telecommunications.

YAN Xue-qin, Master of Translation and Interpretation, School of Humanities, Beijing University of Posts and Telecommunications, Beijing, China; Beijing Foreign Studies University, Beijing, China.
} 
2009). The selection of the address terms depends on the speaker's intention, the social statues of the speaker and the hearer, the relationship between them, the education and the upbringing the speaker received, and the communication mode (Cheng, Wang, \& Zhang, 2014). Thus, little as it is, it carries abundant information of the speaker and the hearer, which, as a result, brings many challenges to its translation.

Nowadays, address terms have been widely studied, ranging from accounts of the origin of a particular appellation (e.g., Ricklefs, 2015; You, 2014), classification and concluding of address terms of a certain society (Yan, 2012), the generalization of particular address terms (e.g., You, 2014; Chen, 2009), to address terms used in a certain group (i.e., homosexuals, female names, etc.) (e.g., Afful \& Mwinlaaru, 2012; Bunzl, 2000; Ogbulogo, 1999), etc. So it is closely culture- and society-bounded, which brings much trouble to its translation. Ogbulogo (1999) said, "address terms attract to themselves a great deal of cultural and linguistic significance as well” (pp. 61-68).

Previous studies on the translation of address terms concentrate on the concluding and analysis of difficulties, deficiencies, differences, or the causes of differences of the translation of them, in a way either taking all the address terms as a whole or focusing on one or two address terms in particular (e.g., Chen, 2010; Yan, 2012), and seldom focus on the translation of the address terms of some particular persons. As the address terms of women in Chinese society is very subtle and of great significance, it is very meaningful and interesting to have a study on it. Besides, Hongloumeng, peak of Chinese classical masterpieces which depicts numerous women characters, is an excellent and ideal material to study the translation of women's address terms. To make up for this, this study concentrates on the translations of two of the 12 ladies' address terms-Lin Daiyu and Xue Baochai by comparing and analyzing the translations of Yang Xianyi and Gladys B. Tayler (hereafter referred as "Yang”) and that of David Hawkes and John Minford (hereafter referred as "Hawkes") in Chapter 28 and hopes to contribute to the growing scholarship on translation of address terms.

\section{Relevance Theory and Translation}

Relevance theory (RT) was first put up by Sperber and Wilson (1986) in Relevance: Communication and Cognition in 1986 and was intended for studying communication and cognition and helping predict people's intuitions. It was developed from Grice's view of communication, therefore, it is also named "Post-Gricean Theory" or "Neo-Gricean Pragmatics" (Yus, 2006). Grice contended that the expressions and recognition of intentions laid the foundations of the inferetial model of communication, and the hearer explains the speaker's communicative behavior by identifying the underlying intention (Yus, 2006). On the basis of that, Sperber and Wilson distinguished the intention into two levels, namely, informative intention and communicative intention, the former one informing the hearer of something and the latter informing the addressee of that informative intention, which means that all that the communicator has to do to communicate a thought is to get the addressee to recognize his/her intention to convey it (Yus, 2006). Following the gist of RT in general, Gutt (2006), student of Sperber and Wilson, applied it into translation.

From Gutt's point of view, translations are acts of the interlingual interpretive use of utterances based on the resemblance of their interpretations (Gutt, 2006). While according to the law of human cognition, the language barriers are not the key obstacles that pave the way of realizing the resemblance but the context. He thought that to be faithful in translation is to produce an intended interpretation of the source text with adequate contextual 
effects realized. To this end, the translator, in order to convey the presumption of optimal relevance, should make the best of the stimulus and the interpretation of the original text as accessible as possible in the target context to minimize the target readers' processing effort.

As we can see, different from functional equivalence approaches, RT's assessment on translation falls into equivalence-based approaches which seeks to modify the translation as closely as possible to the source text in a way that the target reader could catch the intention of the writer without sparing so much efforts.

\section{Analysis of the Translation of Address Terms From RT}

The following cases are extracted from Chapter 28, which demonstrate the characters about Jia Baoyu (hereafter referred as "Baoyu”), Lin Daiyu (hereafter referred as "Daiyu”), and Xue Baochai (hereafter referred as "Baochai”) ${ }^{1}$ and the relationship among them vividly through dialogues. And the address terms in the dialogues change according to the speakers, the context, and the intention of the speakers. Considering the source texts of the two translated versions of Hongloumeng are not the same one, this thesis will present the source texts with the translated ones together.

Example (1)

[ST] 宝钢因笑道: “你正经去罢。吃不吃, 陪着林姑娘走一趟, 他心里打紧的不自在呢。”(Chapter 28, p. 774)

[TT] “You’d better go," Baochai urged him. "Even if you don’t want anything to eat you should keep Daiyu company, she’s not feeling happy.” (Trans. by Yang)

[ST] 宝钔因笑道: “你正经去罢。吃不吃, 陪着林姑娘走一趟, 他心里正不自在呢。何苦来?” (Chapter 28, p. 36)

[TT] "You really ought to go," Baochai said to Baoyu. "Whether you have lunch there or not, you ought to keep Cousin Lin company. She is very upset, you know. Why don’t you?” (Trans. by Hawkes)

Here, Baochai detected that Daiyu was not happy because of Baoyu, so she persuaded Baoyu to keep Daiyu's company so as to delight her. The writer's intention here is to represent the consideration of Baochai who always tried to make peace with others. The word here is a full demonstration of the feature of Baochai. As “林 姑娘” here does not carry too much implication but a normal referential term, it seems very easy to render it. Yang and Hawkes here replaced “林姑娘” by “Daiyu” and “Counsin Lin” respectively, both informing the target readers effectively of the character. Notably, both Yang and Hawkes avoid "Miss" which seems an equivalent of “姑娘”. This process is made with full consideration of the target cognitive environment that in English, “miss” is always used to address unfamiliar young women (Hornby, 2016). Therefore, both Yang and Hawkes here did a great job in terms of the translation of “林姑娘” here.

\footnotetext{
1 Jia Baoyu, Lin Daiyu, and Xue Baochai are the three main characters of Hongloumeng. Lin Daiyu is a cousin of Jia Baoyu, and she moved to live with Jia family after the death of her mother- sister of Jia Baoyu's father. Jia Baoyu and Lin Daiyu loved each other secretly. Xue Baochai is also a cousin of Jia Baoyu and her mother is a sister of Jia Baoyu's mother. And she also moved to Jia family for some reason. Jia Baoyu and Xue Baochai were believed to be couple by destiny. The question is that the girl Jia Baoyu hoped to marry was Lin Daiyu but not Xue Baochai. It was said that Jia Baoyu and Xue Baochai were connected by the jade that Baoyu had from birth and the gold that Xue Baochai wore. This raised Lin Daiyu's jealousy and unhappiness, which is just fully presented by the dialogues above.
} 
Example (2)

[ST] 宝钗笑道: “你叫他快吃了燋黛玉妹妹去罢, 叫他在这里胡犀些什么。”(Chapter 28, p. 776) Yang)

[TT] "Let him finish quickly and join Cousin Lin,” said Baochai. "Why should he fool around here?” (Trans. by

[ST] 宝钗笑道: “你叫他快吃了燋黛玉妹妹去罢。叫他在这里胡闹什么呢?” (Chapter 28, p. 36)

[TT] "You should let him finish quickly, so that he can get back to his Dai-yu,” said Bao-chai blandly. "Don’t make him waste time here with us.” (Trans. by Hawkes)

Following Example 2, here Baoyu worried about Daiyu even though he refused Baochai's suggestion above to have lunch with Daiyu, so he was in a clouds while eating with Baochai and his sisters-Tanchun and Xichun. Here is another example of displaying Baochai's consideration. Tanchun and Xichun both noticed Baoyu's absent-mindedness but neither figured out the reason while Baochai did. She knew that Baoyu worried about Daiyu even though he diclined her proposal to eat with Daiyu just now. Yang and Hawkes rendered “黛玉妹妹” as "Cousin Lin" and "his Daiyu” respectively. Obviously, Daiyu was special to Baoyu and was not just a cousin for him, which Baochai was clearly aware of. So “妹妹” Baochai applied here is beyond the kinship term. In Chinese, “妹妹” always refers to younger sisters of the same generation in a family, and is also a term of endearment among lovers. In this context, “黛玉妹妹” obviously goes beyond the kin term and has an implication of Baoyu's love on her. So Hawkes's "his Daiyu” reveals the closeness of Daiyu and Baoyu and Baoyu's love on Daiyu as well as Baochai's sharp sensibility, which accords with the writer's intention better.

Example (3)

[ST] 林黛玉昨日所恼宝玉的心事早就丢开, 又顾今日的事了, 因说道: “我没这么多大福禁受, 比不得宝姑娘, 什么金什么玉的, 我们不过是草木之人!” (Chapter 28, p. 799)

[TT] Daiyu had forgotten her earlier grievance in her preoccupation with this new incident. "I'm not cut out for such good fortune," she said. "I can't compare with Cousin Baochai and her gold and jade. I'm just as common as any plant or tree.” (Trans. by Yang)

[ST] 黛玉昨日所恼宝玉的心事，早又丢开，只顾今日的事了，因说道: “我没这么大福气禁受，比不得宝姑娘， 什么“金”哪“玉”的! 我们不过是个草木人儿罢了!” (Chapter 28, p. 58)

[TT] "I'm not equal to the honour," she said. "You forget, I'm not in the gold and jade class like you and your Cousin Bao. I'm only a common little wall-flower!” (Trans. by Hawkes)

Here, Daiyu got unhappy again but for a different cause. This time she felt herself neglected in Jia family for the reason that imperial concubine Jia's rewards to Baoyu and Baochai were the same but Daiyu's, which strengthened the rumor that Baoyu and Baochai were coupled from birth by destiny. And she was just an outsider and could not mate Baoyu for her low class. So here, “宝姑娘” has an implication of high class and respect, and by addressing Baochai as “宝姑娘”, Daiyu actually showed her jealousy and discontent. So “Cousin Bao” applied by Yang failed to convey Daiyu's jealousy and self-depreciation while "your Cousin Bao" revealed Daiyu's mood better. By adding “your” before “Cousin Bao”, Hawkes precisely conveyed Daiyu’s mental activity that she was not in the same rank as Baoyu and Baochai as well as that she was not so close to Baoyu as Baochai. So in terms of this context, Hawkes did better in the translation of “宝姑娘” than Yang. 
Example (4)

[ST] 林黛玉道: “你也不用说誓, 我很知道你心里有“妹妹”, 但只是见了 “姐姐”, 就把 “妹妹”忘了。” (Chapter 28, p. 798)

[TT] “There's no need to swear. I know I have a place in your heart. But whenever you see her, you forget all about me.” (Trans. by Yang)

[ST] 黛玉道: “你也不用起誓, 我很知道, 你心里有 “妹妹”, 但只是见了“姐姐”, 就把“妹妹”忘了。” (Chapter 28, p. 58)

[TT] "There's no need for you to swear," said Dai-yu. "I know very well that Cousin Dai has a place in your heart. The trouble is that as soon as Cousin Chai comes along, Cousin Dai gets forgotten.” (Trans. by Hawkes)

Here, Daiyu's attention shifted from the rumor of "gold and jade” to Baoyu's heart as Baoyu expressed his special feeling for her. Daiyu’s words here is to complain about Baoyu’s preference to Baichai to her. “妹妹” and “姐姐” are both kin terms, “妹妹” referring to herself and “姐姐” to “Baochai”, and the two address terms are from the perspective of Baoyu. Yang rendered them into "I" and "her" respectively, while Hawkes translated them into “Cousin Dai” and “Cousin Chai”. In English, “妹妹” and “姐姐” are the same word, so the literal translation here may confuse the readers. Neither Yang nor Hawkes fell into the trap, both of them finding their own way to distinguish the two address terms which are easy for the target readers to grasp the meaning of Daiyu's words. However, Daiyu is a sentimental girl who would not tell her feeling straightly, which is why the writer portrays the comparison through Daiyu’s words in this way that Daiyu addresses herself as “妹妹” rather than "me" or "I". Therefore, considering the writer's intention, Hawkes did a better job than Yang in terms of the translations of “妹妹” and “姐姐” in this context.

As we can see, address terms Cao applied in Hongloumeng in different contexts are all out of full consideration, which has great significance on the portraying of the characters. So the study of their translation can not only help us to appreciate this masterpiece fully, but also inspire us how to deal with the translation of address terms.

\section{Conclusion}

Through the comparison between the translation of address terms by Yang and Hawkes in the extracted chapter from the perspective of relevance theory, this thesis has the following findings:

(1) RT is very powerful in terms of assessing the translation of address terms;

(2) Address terms contain abundant and different information in different contexts (Examples 2, 3, \& 4);

(3) The study of address terms translation must be put in the specific context (Examples 1, 2, 3, \& 4);

(4) The translation of one address term in a specific context can be different as long as it accords with the writer's intention (Example 1).

These findings have a number of implications. Firstly, they contribute to the growing scholarship of translation of address terms; secondly, they certify the powerful explanation of RT in translation; thirdly, it could inspire the translation activities in literature; fourthly, as address terms are part of communication, the thesis has a significance on intercultural communication. Further studies could consider other address terms in Hongloumeng and address terms in verbal communication against the social and cultural background. 


\section{References}

Afful, J. B. A., \& Mwinlaaru, I. N. (2012). When sir and madam are not: Address terms and reference terms students use for faculty in a Ghanaian university. Sociolinguistic Studies, 6(3), 491-517.

Bunzl, M. (2000). Inverted appellation and discursive gender insubordination: An Austrian case study in gay male conversation. Discourse \& Society, 11(2), 207-236.

Cao, X. Q., \& Gao, E. (1999). A dream of red mansions. (X. Y. Yang \& G. Yang, Trans.). Beijing: Foreign Languages Press.

Cao, X. Q., \& Gao, E. (2012). The story of the stone. (D. Hawkes \& J. Minford, Trans.). Shanghai: Shanghai Foreign Language Education Press.

Chen, J. P. (2009). Generalization of address term—“JieJie” in Hongloumeng. A Dream of Red Mansions, 2, 304-318.

Chen, Q. (2010). Cultural differences in Chinese and English address terms. Journal of Language Teaching and Research, 1(6), 898-900.

Chen, X., Wang, J. Y., \& Zhang, C. Y. (2014). Register conformity in translation of addressing terms in literary texts. Foreign Language Research, 5, 81-84.

Gao, C. (2014). The vagueness in Chinese address terms. Theory and Practice in Language Studies, 4(12), 2614-2618.

Gutt, E. A. (2006). Approaches to translation: Relevance theory. In K. Brown (Ed.), Encyclopedia of language \& linguistics (2nd ed.). Amsterdam: Elsevier.

Hornby, A. S.(2016). Oxford advanced learner's dictionary (9th ed.). Shanghai: The Commercial Press.

Hu, J. B. (2009). An overview of swearword study in China. Journal of Southwest Agricultural University (Social Science Edition), 2, 137-142.

Matthews, P. H. (2005). The concise Oxford dictionary of linguistics. Oxford: Oxford University Press.

Me, X. Y. (2008). Address terms equal to appellation-Distinguishing the concept of address terms and appellation. Foreign Language Education, 4, 20-24.

Ogbulogo, C. (1999). Names as discourse: A study of igbo female names. Journal of Cultural Studies,1(1), 61-68.

Ricklefs, M. (2015). The origin of Prince Mangkunagara I's appellation as the catcher of souls. Bijdragen Tot De Taal-, Land-En Volkenkunde, 171(4), 543-548.

Sperber, D., \& Wilson, D. (1986). Relevance: Communication \& cognition (2nd ed.). Oxford: BlackWell.

Yin, F. L. (2003). Pragmatic functions and translation of vocatives in English and Chinese. Chinese Translators Journal, 3, 28-30.

You, C. (2014). Analysis on the generalization of the address term "teacher" in Chinese from the perspective of sociolinguistics. Theory and Practice in Language Studies, 4(3), 575-580.

Yus, F. (2006). Relevance theory. In K. Brown (Ed.), Encyclopedia of language \& linguistics (2nd ed.). Amsterdam: Elsevier. 